\title{
AN ASSESSMENT OF THE SINGAPORE SKILLS DEVELOPMENT SYSTEM: DOES IT CONSTITUTE A VIABLE MODEL FOR OTHER DEVELOPING NATIONS ?
}

\author{
Sarosh Kuruvilla \\ School of Industrial and Labor Relations \\ Cornell University. \\ Christopher L. Erickson \\ Anderson School of Management \\ UCLA \\ Alvin Hwang \\ Lubin School of Business \\ Pace University
}

May 2001

Address Correspondence to

Sarosh Kuruvilla

156 Ives Hall

Cornell University

Ithaca, NY 14853-3901

Email:sck4@cornell.edu

Acknowledgements: We thank Stephen Frenkel, George Boyer and Rodney Chua for comments on a previous version. 


\title{
AN ASSESSMENT OF THE SINGAPORE SKILLS DEVELOPMENT SYSTEM: DOES IT CONSTITUTE A VIABLE MODEL FOR OTHER DEVELOPING NATIONS ?
}

\begin{abstract}
In this paper, we briefly describe the institutional background to Singapore's successful national skills development model. We devise a tentative framework to evaluate national level skills development efforts, and we use it to assess the Singapore model. We argue that the model has the potential to constantly move towards higher skills equilibria, and in those terms, it is successful. However, we question the long-term sustainability of the model, and whether it is transferable to other developing nations. We outline several useful principles that other nations might use in organizing their own skills development systems
\end{abstract}

Keywords: Singapore, national skills development, skill formation, developing countries, national human resource policy, labor 


\section{INTRODUCTION}

Improving the national skill set is clearly an important policy issue for all countries. There is a large literature, for example, pointing to a strong relationship between investments in human capital and economic growth (e.g., Romer, 1986; Lucas 1988; Solow 1956; Azariades and Drazen 1991), while trade theories (e.g. the HekscherOhlin model) stress the quality of national human resources as a critical factor in determining comparative advantage (e.g. Wood, 1994; Godfrey, 1997). The need to improve the quality of human resources is particularly important for developing nations, given its importance in the attraction of foreign direct investment (Koike, 1996; Kuruvilla, 1997). And although the developing world accounts for a steadily increasing share of world manufacturing (partly driven by lower wages and costs in that world), competitive advantage based on low wages is inherently a transitory phenomenon: sooner or later, developing countries will face the need to "upskill" as other lower cost producers emerge.

The aim of this paper is to assess the Singapore skills development system (hereafter SSDS) and to examine its potential to be a model for developing nations. ${ }^{1}$ Singapore is the best known example of a nation that has successfully and continuously upskilled its workforce over the last 40 years. The skills development system surely contributes to Singapore's consistent top rankings in comparative surveys of human resource development. ${ }^{2}$ And the Singapore system, which is anchored and run by the government in collaboration with the private sector, appears to debunk the conventional wisdom that governments are notoriously poor at organizing and administering skills development, particularly on a national scale. In fact, it seems to provide a rare, but good example of a concerted national effort involving collaboration between private sector and government (Singh 1990). Yet, there has been no systematic assessment of the system.

To assess the system (given the absence of established frameworks for evaluation of national skills development efforts), we develop a framework that focuses on focuses on institutional pre-requisites, linkages to other institutions, the degree to which the private sector is involved, and the process by which the system works. We also 
specifically examine the issue of long-term sustainability of the system, and its potential for being a model for developing nations.

\title{
2. KEY FEATURES OF THE SINGAPORE SYSTEM OF SKILLS DEVELOPMENT
}

\begin{abstract}
We briefly highlight the main features of the SSDS (for a more detailed explication of the system see Kuruvilla and Chua 2000, and Ashton et. al. 1999).
\end{abstract}

(a) Structure

Broadly speaking, and as the system exists currently (the structures and institutions have changed considerably over-time, and as we shall argue, the frequent changes are also an important ingredient in the success of the system), there are several key actors and institutions. Perhaps the most important institution is the Ministry of Trade and Industry (MITI), which is responsible for broad economic development policies (Ashton et al, 1999). Supporting the Ministry are a range of semi-autonomous agencies, one of which is the Economic Development Board (EDB), an agency that has the primary function of attracting foreign direct investment and meeting foreign investors' demands for the required skilled personnel. This linkage is important in and of itself (economic development and skills) but the EDB has also worked together with other agencies, such as the Productivity and Standards Board, the Institute Technical Education, and other industry-specific bodies such as the Precision Engineering Institute, to meet the skills demands of investors over the years.

A second key institution in the SSDS is the Council for Professional and Technical Education (CPTE), an independent body that takes overall responsibility for matching the demand and supply for skills in the economy. Based on existing levels and estimated future needs, this body works together with different parts of the education system (universities, polytechnics and schools) and skills development institutions (Institute of Technical Education, Productivity and Standards Board, and other industry specific training institutes) to ensure the supply of sufficient numbers of workers with the desired level of skills for industry requirements. The CTPE serves the all-important 
coordination functions, gathering the required information to provide targets for several other agencies. A third key actor is the Ministry of Education which has direct jurisdiction over schools, polytechnics, universities and the Institute of Technical Education.

In general, the EDB focuses on skills for economic development through the focus on meeting investors' skills needs, the CTPE focuses on overall coordination, and the Ministry of Education focuses on long term human resource development, while a range of other institutions focus on short and medium term skills needs, notably vocational skills. These include various vocational training institutions, such as the Institute for Technical Education, and various other industry-specific institutes. Finally, the Productivity and Standards Board (PSB) focuses on productivity improvements in different industries and firms, and points those firms to appropriate skills training institutions. In this way, the government helps firm-level skills development. The PSB thus focuses on workers who are already in the workforce, while other institutions focus on those about to enter (or re-enter) the workforce.

An important aspect of the SSDS, as Ashton et al (1999) noted, are the channels of communication across different institutions. These channels of communication exist at different levels in the SDSS, and include high level official inter-ministry and interagency meetings among bodies such as the Ministry of Trade and Industry, the Economic Development Board, and the Council for Professional and Technical Education. MITI representatives also sit on various boards and councils in the range of higher education and training institutions to ensure that workforce skills demands can be translated into meaningful goals in these institutions at the operational level. On the supply side, the Ministry of Education, higher educational institutions and worker training and upgrading institutions also participate in feedback on their existing capacity and observed trends while working together with CPTE in identifying areas that have to be addressed to meet estimated future needs. As an example, corporate training through PSB programs can be funded by the Skills Development Fund, a levy system administered by the EDB, with both agencies working together to ensure that skills training is easily accessible to workers. In addition to this multi-level inter-locking system of communication and interactions in the SSDS, the Boards of Management of each of these institutions is 
tripartite in nature (representation by employers, government and labor unions), which ensures that different interests are heard and permits the development of a national consensus.

A pictorial depiction of the primary structure is provided in Figure 1. This figure does not purport to be an indication of organizational structure but more an indication of where the different institutions are positioned in relation to economic and developmental needs of the country. The solid lines indicate reporting relationships while the broken lines indicate instances where there is coordination and communication between the parties. The broken lines do not adequately reflect the degree and nature of institutional cooperation, however, and this aspect is discussed later in this paper.

(b). The Linkage between Economic Development Strategies and Skills Development.

Kuruvilla and Chua (2000) noted the tight “coupling” between economic development strategies in Singapore and its skills development policies. Tracing Singapore's economic development through each of its four main stages of economic development, they showed how the state was able to mold its national human resource policy to provide the skills necessary for each phase of development. During the import substitution industrialization period (1959-1965), the national imperative was to have a standardized education system that not only provided the science, math, and technical education required for economic development, but one that also aimed to ensure that ethnic roots and values were not eroded through the focus on basic literacy and technology requirements. A pragmatic expression of this philosophy was the option of schools that use an ethnic language, such as Chinese, Malay or Hindi, as the main medium of instruction while also requiring English to be taught. There were also schools that used English as the main medium of instruction with the ethnic language as a required second language. Therefore, bilingualism was a key part of the curriculum. The short-term needs for trained technicians were met through a series of secondary vocational institutions and polytechnics. Managerial training during this phase was provided by the manpower development unit of the Economic Development Board, the agency that was established in 1961 and given the responsibility for addressing industry 
needs of the economy. The results show that primary and secondary school enrolment increased by 33\% and 93\% during this period, while college enrolment increased by 69\%. The new polytechnics graduated around 1200 workers during this period.

The import-substitution phase of the economic development cycle was followed by an export-oriented industrialization phase from 1966 to 1973. With this new development strategy, attracting foreign investment became the main focus of the government, as foreign investors bring along with them not only capital, but also technology and access to foreign markets. A key imperative of this phase was the need to meet demands for technically trained manpower for these foreign investments. While an early step to meet the demand for higher skilled personnel was through the establishment of local training institutions that focused on technical skills (e.g., the Singapore Technical Training Institute to train instructors for other vocational institutions), the EDB also realized the importance of technology transfers from institutions in more advanced countries. As a result, the EDB commenced funding overseas training for selected workers through its overseas training scheme. This was complemented by the EDB's initial articulation of its model of skills and technology transfer (to be discussed below), where specific foreign corporations were provided finance and infrastructure to set up training centers in Singapore. These initiatives contributed to a large increase in technical education and the creation of 800 OTS training positions.

In Phase 3 (1973-1984) of Singapore's economic development, the export oriented strategy moved into higher value-added and more technologically-advanced products that required both general skills (vocational and technical training for occupations such as fitters, electricians, welders) and specialized skills germane to the industries that were growing as a result of foreign investment. To facilitate this transition, there were three major government initiatives, largely through the EDB. First, the Vocational and Industrial Training Board was established in 1979 to be the largest supplier of all general skills, through its jurisdiction over all existing technical, vocational and commercial training institutions. Second, the EDB intensified its model of technology transfer for meeting specific skills, by inducing foreign companies to take the initiative in training with training subsidies and grants. And third, the education system was also reformed, culminating in the NES (new educational system), which is described 
in greater detail below. In essence, however, the new educational system, akin to the German model, provides for the supply of both technical and vocational students as well as those heading to the university. This education reform was also buttressed by curricular reform at the National University of Singapore, and was coupled with the creation of the Nanyang Technological University as well as two new polytechnics, making a total of four polytechnics in all.

In the most recent phase of economic development since the mid-1980s, the preoccupation has been with enhancing creativity among the young and with developing entrepreneurial risk-taking behavior. This transition is perhaps the most challenging, as creativity and entrepreneurial risk-taking behavior requires a huge change in attitude for individuals to take personal responsibility for ideas and direction rather than for the state to set an orderly pace of development for its people. While part of the rationale for this new focus is that it is the next natural economic developmental move towards becoming a major investment force in the region, this new focus also reflects an attempt to respond to industry feedback that Singapore graduates were analytically sound and could execute well-defined tasks, but were often stymied when problems and instructions were not clear or when faced with situations that demanded innovativeness and creativity (Kuruvilla and Chua, 2000).

\section{(c) The FDI, Skills, and Technology Transfer Model}

Perhaps the most important and unique feature of the SSDS has been to provide incentives for foreign investors to establish training centers in collaboration with the state, while guaranteeing the foreign investors the rights to hire a proportion of the graduates from these training centers. This ensures that foreign investors will not face skill shortages in a tight labor market, given that they have some control over the supply of skilled people.

The model initially started on a small scale where the Economic Development Board targeted specific companies such as Rollei (Germany), Phillips (Netherlands) and Tata (India). The incentives offered to the different companies varied. For example, the EDB provided Rollei with several major incentives to invest in Singapore and establish its training center. It granted Rollei the right of refusal for a period of 10 years: i.e., during this period the wide range of products that Rollei could make was placed under a "control 
of manufacture ordnance" which required all other potential manufacturers of the same products to seek a license to produce them in Singapore (Kuruvilla and Chua, 2000). Such a license would be granted only if Rollei declined to manufacture these items in Singapore. In the Tata case, the government provided loan finance to the group to set up their business, reasonable land rents, and paid for the purchase of training equipment and materials, as well as $70 \%$ of operating costs.

These centers were organized on similar lines, however. The principle was that the companies offering the training would have the right to hire the graduates. For example, $44 \%$ of the Rollei institute graduates were employed by Rollei and other German firms. Another significant feature was that the EDB participated in the management of these centers, sometimes taking them over after some years, or integrating these centers with the existing vocational training apparatus in Singapore.

With the success of these individual centers in the early 1980s, and the need for a much higher flow of skills given the higher levels of foreign investment, the EDB expanded its focus to create training centers funded jointly by other governments and itself. The logic here was that if foreign governments could be persuaded to invest in skills development in Singapore, that would be an important incentive for firms from that foreign country to also invest in Singapore. Accordingly, The Japan-Singapore Government Training Center (specializing in metal machining, electrical fitting, electronics instrumentation), The German-Singapore Institute for production Technology, the French-Singapore Institute for Electro-technology, and the Japan-Singapore Institute of Software technology were established during the 1979-1984 period. The operating principles were similar to the individual company centers. There was some degree of cost sharing by the two governments, the expertise and training materials were provided by the investing companies and governments, and companies from those countries were guaranteed that their demands for graduates would be met.

With continued economic growth and the need for a larger supply of skilled craftsmen and technicians, several of these institutes were later combined to form much larger institutions. Kuruvilla and Chua (2000) describe the Institute for Precision technology (PEI), for example, created out of the erstwhile Rollei institute, which itself was taken over by the Brown-Boveri government training center following the collapse 
of Rollei-Werke in Germany. The PEI was run by the government, but with many foreign firms as partners; the staff and instructors were trained at the various companies abroad, and included within it several different centers such as the Siemens Nixdorf-EDB center for Advanced die and Tool making, the Bridgeport-EDB Computer numerical control library, and the Mitutyo-EDB Metrology laboratory. Similarly, The GermanSingapore Institute was transformed into a full computer industry training center, with firms from several countries participating to create a fully integrated center servicing the needs of the computer industry.

This model of cost sharing with foreign investors and the Singapore government (through the EDB) was successful not only at generating the skills required for foreign investors in the short-run, but also served as centers of training for future transferable skills (or, general human capital) as well, by harnessing different foreign firms' unique expertise. Thus, the German-Singapore institute became an industry training center, with world leaders in several different technologies providing training. And, Japanese electronics companies such as Seiko, Sankyo Deiki, Matsushita and Mitutyo provided expertise in surface mount technology, IC design, and computer numerical control technology; European companies such as Siemens, Asea, and Carl Zeiss contributed equipment and skills in the areas of artificial intelligence, laser and vision technology; and Hewlett Packard and Auto Desk provided training and expertise in CAD/CAM robotics and simulation software. This training centers model was soon expanded to several other industries as well

While there is evidence (Vente and Chow, 1984) to suggest that these institutes have been crucial in meeting the demand for skills, this is also an example of a government being able to play a leading role in providing incentives to foreign investors to invest in skills development in a way that benefits both foreign companies and the home-country workers. It also demonstrates the potential value of linking national economic development policy to skills development policy.

(d) The Skills Development Fund.

The Skills Development Fund System (SDF) represents the government's efforts to encourage all firms to invest in skills development. Enacted in 1984, the legislation 
requires employers to contribute $1 \%$ of gross salary of all employees earning less than 1000 S \$ per month (revised upward to \$1500 in July 2000) into the skills development fund. They can recoup $80 \%$ of their contribution by requesting training grants for skills development. The training grants are structured such that firms providing training in skills that are in demand, or have training plans that cover over $50 \%$ of the workforce, are provided higher sums, while companies that continue to use low skilled workers in low cost operations are penalized. Firms can apply for these grants electronically, through a system called Skillsnet, and as a further incentive to invest in skills, National Training Awards are given to companies that do particularly well in terms of workforce training. By 1990, roughly 30\% of the workforce had undergone some kind of training under this system, and the average training expense of corporations was about $2.4 \%$ of total payroll costs. By 1996, roughly 33\% of the workforce was receiving training, and corporations were spending $3.6 \%$ of their payroll on training.

(e) Long Term Skills Development: Education Policy

While the EDB has been focusing on ensuring that skills are available for economic development, the Council for Professional and Technical Education (CPTE) has established specific targets and policies for the various components of the education and training system, notably the universities, polytechnics, and schools. In 1979, the Ministry of education undertook a sweeping review of education and proposed the NES (the new education system) at the school level. The new education system emphasized six years of primary education (with a major focus on math, science, and English), four years of secondary education during which students are channeled into arts, commerce, science, and technical streams, followed by the comprehensive British based General Certificate of Education - Ordinary Level (commonly referred to as the GCE "O" level) Examinations, which would qualify students for junior college, then the GCE - Advanced Level Examination (GCE "A" Level) to qualify for university. The two common examinations (GCE "O” and GCE "A") aimed for a consistent standard, and students who did not pass these examinations were channeled into the vocational training area to the various institutes described earlier. Coupled with the NES, there were major curriculum changes at the university level, particularly in engineering, to ensure that long-term technical skills were produced. 
Since the 1990s, education policy has been rethought again, to focus on increasing creativity in school children. This is being attempted through changes in the structure of examinations, more project based methods of evaluation, more research and term papers, and other methods to encourage students to "think outside the box." The thinking skills program launched by the Prime Minister in 1996 was designed to address the perception that Singapore graduates are analytically sound, but lack creativity, based on feedback from industry. Education and curriculum reform was also deemed necessary given Singapore's goal of becoming a regional research and development center, and the estimated shortfall in the number of research scientists and engineers. The goal of becoming a "knowledge economy" continues to motivate questioning of the education system. The Ministry of Education (MOE) is targeting 5 areas for redesign and improvement in the coming years: 1 . Conducive school environment, 2. Curriculum and assessment system, 3. Teacher development, 4. Pre- and post-school education, and 5. Developing Singapore as an education hub. In line with this drive, the labor organization, The National Trade Union Congress (NTUC), also proposed Productivity Action 21 (ProAct 21), a program of learning and upgrading to keep its members employable throughout their working lives. Thus, the continuous learning culture is being operationalized through different public agencies, both government and labor organizations. These initiatives are still in their early stages, however.

\section{(f) Summary}

The key features described above are suggestive of a system where there is a strong degree of centralized articulation and planning of skills development needs, coupled with an innovative government-private sector partnership that integrates foreign direct investment and technology transfer in ways that provide necessary skills on relatively short notice. Further, the SDF works to ensure that firms continually invest in skills formation and upgradation, while the education system has been frequently reevaluated in light of the country's skills needs. 


\section{ASSESSING THE SINGAPORE SYSTEM OF SKILLS DEVELOPMENT}

How should the SSDS be assessed? At the outset, we must admit that we know of no established framework or heuristic that permits a complete assessment of the SSDS. And, our questions to various Singapore government officials yielded little in terms of a consistent framework that they use to assess how the SDSS is performing. Officials seem to take a problem-oriented view in their assessment of the system: i.e., if they hear of or perceive problems, they react to them, but in general, they appear to rely on broad and general developmental, labor market, and educational indicators, whose connection to specific skills development needs were at times tenuous at best.

\section{(a) General Indicators}

Several broad and general indicators have been used by policy makers to evaluate the overall success of skills formation and development policies. These include the general level of economic growth, the extent of foreign direct investment, the degree to which exports are composed of higher value added items, the degree to which there are skills mismatches generally, and the rates of growth of productivity (both nationally and disaggregated by industry). Different agencies place different weights on some of these measures ---economic growth and FDI, for example, are of greater concern to the EDB, while increase in value added exports and productivity growth are of greater importance to the PSB. Similarly, the average annual growth rates of graduates is a key general statistic for universities and vocational institutions (see Table 1).

The macro data in Table 1 appear to indicate the success of skills development efforts in Singapore. Economic growth rates have been high, consistently among the highest in the region. Foreign direct investment has also grown, also to the highest in ASEAN. Perhaps most importantly, annual average growth rates in productivity are high, much higher than most countries in the world. We could not find longitudinal data on the composition of exports, but we note that the value added per worker rose from S\$ 42000 to S\$ 83000 in the manufacturing sector during 1988-1998, while corresponding figures for the service sector increased from S\$ 52000 to S\$ 92700 (Singapore 1998 Statistical Highlights). 


\section{-- Table 1 here --}

One overall measure that is occasionally used to evaluate the success of training at the national level is data on skill mismatches. This is most commonly measured by comparing the unemployment rate with the job vacancy rate, although many countries have more specific data on skills mismatches. The implicit assumption here is that if labor market institutions are effective and labor market information is transparent, it should be possible to convert those unemployed to fill the vacant jobs, controlling for other determinants of unemployment. This data for 1996-1999 is shown below in Table 2. These data are not easily interpretable, given that the Asian financial crisis had impacted Singapore during this period. Hence, unemployment rates were much lower than job vacancy rates in 1996 and 1997, but higher than job vacancy rates in 1998 and 1999. Further, the large number of older workers who have been retrenched and are perhaps not capable of being retrained will also affect these figures. The figures do show an improvement in 2000, however.

\section{-- Table 2 HERE --}

Although subject to many reservations, the data from Tables 1 and 2 suggest some support for the general success of Singapore's skills development efforts. Below, we turn to more specific indicators.

\section{(b) Performance of Specific Components}

Studies of the effectiveness of particular training systems or programs or particular education systems are common in the literature (See, for example, Bishop 1997; Keep and Mayhew 1999). This approach can be utilized in the Singapore case as well, with separate investigations as to how the core institutions and programs work. We will focus here on some of the key components, notably, the education system, the skills development system, and some vocational training institutions.

It is worth noting that there are several different ways in which education systems are evaluated. Commonly, measures of quality and quantity are used. Quality measures focus on comparative performance, such as the international comparison of scores on certain subject related tests. In this measure, a high relative test score is presumed to 
indicate a better education system. The best known of such measures is the third international math and science study, conducted on a group of 13 year olds from several Western and Asian countries. Singapore students stood first in both science and math (Beaton, 1996). In another study of 18 year olds, Singapore students stood second in chemistry and physics and first in biology. By these measures of relative achievement, therefore, the Singapore education system performs extremely well. ${ }^{3}$

Measures of quantity (or the output of the education system) even more unambiguously suggest effectiveness of the system. Table 3 presents a picture of the Singapore workforce in terms of the distribution of education for the years 1990 and 2000, while Table 4 shows the growth rate of output from the various academic institutions, including polytechnics, vocational training institutes and courses from the Productivity and Standards Boards.

\section{-- Tables 3 and 4 HERE --}

An alternate measure of the education and training system focuses on "sufficiency" and comes from the manpower requirements perspective. Viewed from this perspective, jobs and occupations have specific schooling requirements, and thus the occupational skill requirements are driven by forces such as consumer demand and technological change The key question here is whether policies have been undertaken such that supply and demand are in equilibrium. If not, there is either undereducation (low supply of skilled workers), which creates a bottleneck to economic growth or an "overeducation" where individuals' schooling and training exceed the amount that is presumed to be "required" for those jobs. Although we do not have original data that would constitute an adequate test from the manpower requirements perspective, we do have access to surveys of international business executives regarding the Singapore workforce. These international competitiveness rankings are based on both objective assessments about the nation's workforce quality, as well as subjective assessments by international executives. Table 5 shows Singapore's rankings on these dimensions. This table does not show relative improvement in skills development efforts (measured by perceptions of sufficiency relative to other countries by the international business community), given the decline in Singapore's rank between 1988 and 2000.

\section{-- Table 5 HERE --}


The SDF's can be evaluated in terms of the total number of persons undergoing training, and over the years, this levy/grant system has ensured that roughly one out of three Singaporeans receives some training through SDF activities every year. An important indirect outcome of the SDF's, perhaps urged on by the National Training Award Scheme, is a gradual increase in the average corporate budget (as a percentage of payroll costs) for training, and this has increased from 1\% of payroll in 1986 to $3.6 \%$ of payroll in 1996. It remained at 3.6\% during the 1996-2000 period (Table 6).

\section{-- Table 6 HERE --}

A key question is whether this investment in training has paid off in terms of increasing productivity. Table 1 indicated that average levels of productivity growth were high in Singapore. There is also evidence to suggest that the industries that were the biggest investors in training (as per SDF figures) are also the most productive. Kuruvilla and Chua (2000) cite the example of the computer disk drive and peripherals industry, which has been the most intensive user of SDF, and the value added per worker in dollar terms is $\mathrm{S} \$ 138000$, about twice the average in comparable manufacturing firms. Similarly, value added in dollar terms has been very high in the transport and communications industry. However, there are inherent limitations of these measures in that they do not indicate whether training alone (and specifically SDF-sponsored training) is responsible for the productivity increases. In general however, as Bishop (1997) argues in his wide-ranging survey on employer provided training, there is an inherent difficulty in isolating the separate impact of firm level training on productivity growth.

The evaluation of individual components suggests that Singaporean institutions are effective, although it is not clear that there is a standard to judge them against. It would be more enlightening to be able to link changes in economic growth rates or changes in productivity growth rates to overall skills and education improvement, but such direct causal inferences are inherently problematic.

Thus, these summary measures of specific institutions are generally consistent with the picture that emerged from our discussion of broad macro economic measures. Each of the institutions we examined performs well on measures of quantity, while external evaluations of the quality of Singapore's labor force are high on some 
dimensions, but declining (in terms of the competitiveness rank) in terms of whether the skills of the workforce are sufficient for its current needs.

\section{( c ) Progress towards High Skills Equilibria}

However, sufficient current functioning does not guarantee that these institutions will function effectively in the future, nor does it guarantee that skills development efforts in Singapore will continue to be adequate. What is necessary is some indication of whether the Singapore skills development model is capable of adapting continuously. To assess potential, and we rely on the approach suggested by Finegold and Soskice (1988) to inquire into the capacity of the Singapore system to move to ever higher skills equilibria (see Culpepper 1999 for an example of its application to the German system).

The basic underlying tenet of this approach is that continual development requires movement into higher skills equilibria (HSE). For countries to constantly attain higher skills equilibria, there are certain institutional prerequisites that are necessary. Our approach is to examine whether Singapore shows evidence of these institutional prerequisites. Having the institutional pre-requisites does not, of course, guarantee that movement into higher skills equilibria will be made; the skills development institutions also have to function effectively, which the evidence reviewed above suggests is the case in Singapore.

This approach has the advantage of more universal application, however, without getting bogged down in the measurement of the efficacy of individual components or institutions. One can easily compare across countries as to whether the pre-requisites exist, and if they do, then those nations possess the potential to evolve into states of higher skills equilibrium. The framework is more silent however, on the process through which an entire integrated national skills development system works, which is also a question in which we are interested in terms of assessment. Yet, it is important to see whether Singapore does have the necessary preconditions for HSE.

Finegold and Soskice's (1988) perspective argues that movement to HSE requires that institutional and market conditions favor action on the part of different actors in the system. Individuals, for example, must be willing to invest more in education and 
training, firms must be constantly motivated to increase employee skills, and governments must have motivation to ensure that there are no skills shortages. This action is influenced by both institutional conditions as well as market conditions.

The three institutional and market pre-requisites that Finegold and Soskice emphasize include:

a) Factors that force actors to take a long-term outlook (mostly institutions that counter pressures from capital markets to focus on the short-term).

b) Factors that encourage interfirm cooperation within a competitive environment.

c) Export orientation, or exposure to international competition.

We analyze Singapore with reference to each of these pre-requisites. With regard to the presence of a long term outlook, Finegold and Soskice's argument is that competitive capital markets prevent firms from taking longer-term decisions given the more short term focus on the bottom line. Although capital markets in Singapore are competitive and exert the same pressures, we argue that there are three other factors that encourage the adoption of a longer-term view with respect to skills development. First, we argue that that a tight labor market in Singapore forces employers to take a longerterm perspective with respect to retention and training of employees. Singapore has been at full employment levels for the last two decades, and imports both skilled and unskilled labor. While such tightness could result in considerable turnover (as, for example, in Silicon Valley of California), real turnover rates in Singapore are low and have declined in the 1990s (see Table 7) ${ }^{4}$. We argue that this has resulted from employers' incentives to retain employees, and an institutional/cultural setting that discourages poaching and job-hopping.

\section{-- Table 7 HERE --}

Second, we argue that there is some institutionalized encouragement of job security through labor union activity, and macro-level tripartite agreements (such as the mechanisms put in place during the Asian financial crisis; see Erickson and Kuruvilla 2000) that limit the ability of firms to layoff and retrench freely. In particular, the government plays an important role here. From the perspective of the government, the long term plans that are a basic feature of Singapore's government are built around a consensus between politicians, civil servants, business and labor, such that the long term 
planning process is not derailed for the short term needs of one of the actors. This is one of the benefits of the tripartite structure of Singaporean industrial relations. Third, we argue that individuals also invest in more education and training largely because there is, in Finegold and Soskice's terms, a well defined high status structure of qualifications, where success is measured by qualifications, position and income and there is a clear return to education. Thus, there are significant pressures for actors to take a longer-term perspective.

With regard to the second pre-requisite, the existence of cooperation in a competitive environment, Finegold and Soskice's argument is that firms need to cooperate in the provision of training and skills development. Failure to cooperate has serious consequences, notably that firms would feel that if they invest in training, other firms will "poach" the employee, a condition that is more likely to happen in tight labor markets, ceteris paribus. In Singapore, despite its tight labor market, there is considerable cooperation among firms in the provision of skills. This cooperation among firms is largely a result of government initiatives, particularly through the EDB's model of technology transfer and skills development, which brought together firms initially through collaborative training centers organized by the government and other governments, to industry wide training centers operated by the government where the private sector provided critical skills training to meet their own needs and the companies providing the training were guaranteed that the workers would not take their skills elsewhere in the near-term (see above). The incentives provided to firms to invest in training, and the government's own willingness to fund or build the administrative apparatus for the delivery of skills to the entire industry, are of critical importance in the way in which government has fostered this cooperation. The government's role here is similar to other examples of cooperation between competitive firms, such as in the Emilia Romagna region of Italy, where the local government set up industrial service centers for training to meet the needs of the firms. Thus, there are institutional mechanisms that allow firms to cooperate and share information on the provision of skills for their industry. The Precision Engineering Institute in Singapore is one concrete example of the outcome of this institutional pre-requisite. 
Establishing such cooperative links between otherwise competitive firms are only part of the process of achieving a high skills equilibrium, however. Firms are generally not in a position to look at occupational needs across different sectors, a subject that is more in the bailiwick of state manpower planning departments. However, where there are macro-institutional forums for negotiations between the prime economic actors and government officials (corporatist institutions), the movement towards an HSE is critically enhanced. Such corporatist institutions, argue Streeck and Schmitter (1985), are successful at forging a consensus among decisionmakers to shift investment and skills to high growth sectors, and to also deal with the pain of firm restructuring. Singapore perhaps is ideally placed with regard to this dimension, given its corporatist arrangement where labor through its links to the party forms the third partner to government and business. An example of this is that the governing boards of all the major skills development institutions are tripartite in nature in Singapore.

At the firm level as well, there must be internally cooperative environments for continual innovation and change, particularly in order to motivate workers to gain new skills. The degree of cooperation internally largely depends on the type of labormanagement relations in firms, and the institutional features of the industrial relations system more generally. Firm-level labor-management relations are cooperative due to the enterprise union structure that the government has proscribed, in addition to various industrial relations regulations, such as legislation that limits the subjects of bargaining (job assignments, promotions, transfers, layoffs are not bargainable), and administrative rules that circumscribe the right to strike (see Kuruvilla, 1996). More general industrial relations harmony is achieved, as Kuruvilla (1996) notes, through the tripartite structure that is characteristic of Singapore, where unions have voice in national decision-making, coupled with a consistently high level of economic growth. The unified labor movement (97\% of local unions are affiliated to one federation, the NTUC) also enhances tripartism.

The third critical institutional pre-requisite is the degree of exposure to international competition, which acts as an impetus to a high skill strategy for the government, firms, and individuals. Singapore's economic development since 1965 has been predicated on an export-oriented industrialization strategy. For the government, there has been the sense of a constant threat from other economies in Asia, initially from 
South Korea, Taiwan, and Hong Kong, and more recently from Malaysia, Philippines, China, and India. Singapore based firms are also exposed to international competition, and Singapore is a good example of Katzenstein's (1985) argument that openness of an economy is positively correlated with the development of various institutional structures designed to attract high skill companies.

If having all of the key prerequisites for the development of a high skills equilibrium is a useful way of assessing the SSDS, then Singapore seems to be a good example of a nation that has the capacity to constantly reach new levels of HSE. Thus, broad measures of outcomes suggest that the Singapore system is working, and the discussion on the prerequisites for HSE above suggests that Singapore has the capacity to move constantly into ever higher-skills equilibria. The key unanswered question concerns the HOW, i.e. the process by which success is generated, to which we turn next.

\section{( d ) Processes}

We find that several factors play an important role with regard to the HOW question and we draw heavily previous research (Kuruvilla and Chua 2000, Ashton et al 1999), to identify important process dimensions

Important dimensions include: the fact that it is a concerted national effort, which results in a unity of purpose that enables all the demand- and supply-side institutions to "speak with one voice;" a process that involves uncovering the different views of different institutions, discussions and iterative alignment of views to produce a unified direction; and finally, consistent actions by all the different parties toward maintaining the relevance of skills for industry. This constant effort in alignment of differences that leads to "speaking with one voice" inevitably flows over into changes in governmental agencies that have responsibility of implementing new plans and orders. For example, the Productivity and Standards Board now has a wider ambit that includes quality standards and the Skills Development Fund, than when it started out as the National Productivity Board -which was primarily focused on productivity and skills training. The evolution of the various industry training institutes, such as the Precision Engineering Institute is another example. Thus, the state and the various coordinating mechanisms 
that we discussed earlier contribute to this highly integrated and complex interaction process. By themselves, each of these bodies and interactions is a necessary but not sufficient condition. However, when taken together, they enable effective functioning, as indicated below

Clearly, there is a concerted national effort here. The system operates at different levels, for instance. At the macro economic level, the CPTE sets overall direction for skills development through educational and training institutions. Through the Productivity and Standards Board, firms are constantly fed with productivity data to induce them to take advantage of the Skills Development Fund to train workers. The government works with the private sector to develop training centers and programs for the workers, and those workers are then hired by firms that provide the training. The training centers involve collaboration between different firms in the same industry. The state provides various incentives for corporations to invest in such training. Training is directly linked to foreign investment and economic development.

Relevance is maintained through various feedback loops. For instance, each training institution has ties with the private sector to obtain information and advice on the kind of training that is necessary. The Trade Advisory Council of the Industrial Technical Institute is made up of tripartite members while the SDF's have a tripartite advisory council. Since corporations help establish these training centers, they also have an interest in maintaining relevance. Relevance is further enhanced through the PSB's efforts at monitoring productivity growth throughout the economy. Finally, the fact that all of the different institutions work on the basis of a long-term economic development plan that is widely disseminated enables different departmental heads to see the wider relevance of what they are doing; it provides an underlying anchor for their efforts.

A further extension of the relevance dimension concerns the constant consolidation and reorganization of institutions. For instance, The Institute for Technical Education, now the primary body for vocational training, actually has evolved through different structural forms, culminating in the merger of the Industrial Training Board, the Adult Education Board, and the Vocational and Industrial Training Board. The process of consolidation also enhances the diffusion of skills training. In every case, the different centers established by the individual companies and governments were taken over by the 
state. The state thus acquires ownership of the curriculum and ensures its further diffusion by distributing that curriculum throughout the web of institutions.

Consolidation and reorganization also follows as a function of the need to collaborate with other institutions. For instance, when apprenticeship training needed to be improved in 1993, the PSB along with the SDF jointly launched the OJT 2000 plan that aimed to train 70,000 apprentices by the year 2000. Similarly, the PSB and the ITE have worked together to put in place a comprehensive system of continuing education for working adults without secondary school education.

Another aspect that clearly helps this synergy is the quality of leadership and organizational culture of different institutions. Much has been written about the efficiency and organizational culture of Singapore bureaucrats; Schein (1996), in his study of the EDB, labels the culture one of strategic pragmatism. He argues that the Singapore bureaucracy has managed the development of teamwork on the one hand while simultaneously rewarding individual achievements. Our interviews with various skills development personnel also made it clear that the nature and experience of leadership of the different institutions contributed substantially to the commonality of purpose throughout the system. Most leaders have rotated through several key policy positions in different institutions. Schein, for example points out that Ngiam Tong Dow, the chairman of the EDB from 1975-1981, previously served as permanent secretary to the Ministry of Trade and Industry, then served in the Ministry of Finance, and also as permanent secretary in the Prime Minister's office before becoming EDB chairman. To take another example, Lim Boon Heng, currently head of the National Trades Union Congress, is also a Minister in the government, and functions as the Chairman of the Skills Development Fund Board., Previously, he served as the head of the Productivity and Standards board. Job rotation among top leaders, thus, also promotes the commonality of purpose.

Our findings are consistent with those of Ashton et al. (1999), in that the channels of communication across different state agencies are a key element in their success; yet, there is considerably more at work than the channels they suggest. Our findings are, also consistent with the observation made by Mark Daniels of Bain and Company (an international management consulting firm): " I think that the people who move into government are very well trained, very open minded and have an attitude 
which is much akin to the private sector than you would find in a standard American or certainly European bureaucracy," and he also notes "there is an alignment of resources, the education system, the financing, the use of CPF funds, the government's policies, all aligned behind some well thought out and structured goals" (Kuruvilla and Chua 2000).

It is important to note that some of these key processes suggest prior design and intention (such as the job rotation among leaders, the structural links that facilitate common decisionmaking, and the collaboration across different agencies). But other processes have evolved over time, (e.g., the degree of consensus among civil servants about the broader economic goals of the country). More research is needed on these processes to tease out underlying constructs however.

\section{LONG TERM SUSTAINABILITY OF THE SINGAPORE SKILLS DEVELOPMENT SYSTEM}

The SSDS seems to have worked well. The well known well known argument of Young (1991) and Krugman(1994) that Singapore's growth has largely been driven by larger inputs of capital and labor rather than productivity growth may have been true for the pre-1996 period, but thereafter productivity growth in Singapore has been high, reaching almost 5.8\% in 1999 (PSB Annual report, 1999 Statistics). The SSDS' has also worked well during the Asian financial Crisis belying the argument of Ashton et al, (1999) that skills development works well during periods of high growth, but not during periods of low growth.

Our rationale, then, for posing the long-term sustainability question relates to the newly articulated long-term vision for the development of Singapore. The key question is whether the existing system of skills development is sufficient to meet the new goals. From what we have been able to gather, these still-developing long term goals amount to attempting to develop a culture of innovation so as to become a globally competitive knowledge economy and research and development hub, with Silicon Valley as a model. ${ }^{5}$

In order to speculate about the future success of skills development in the light of these goals, we use Finegold's (1999) concept of "high skill ecosystems." Finegold (1999) and Kenney (1999) have written about the factors that are important in the 
creation of self sustaining high skills ecosystems (such as Silicon Valley, Cambridge (UK), the Boston Corridor, etc.).

Finegold (1999) uses a biological analogy to characterize the factors that help create a self sustaining high skills ecosystem; namely a catalyst, fuel or nourishment, a supportive host environment, and a high degree of interdependence for the separate organisms to grow. We discuss the first three conditions with reference to Singapore. ${ }^{6}$

(i) Catalysts: A key stimulant or catalyst in the growth of Silicon Valley was the large surge in department of defense funding in the 1940s and 1950s that helped create the cluster of aerospace firms in Southern California. The growth of Hewlett Packard and the links between Stanford and IT industry was yet another catalyst. Research universities thus played a vital role for the development of HSE. Singapore's universities are not similar to Stanford and Berkeley here in terms of either fundamental research or in incubating new high tech startups. Although government efforts at developing the infrastructure for the high technology industry are surely a "muscular" stimulus, universities also need to provide the "brain" stimuli.

(ii) Nourishment: Synergistic relationships between research universities and surrounding firms that hire their graduates become self-sustaining. Thus steady intake of human capital needs to be coupled with availability of financial capital. While Singapore does turn out graduates, it is not clear that they turn out enough. Kuruvilla and Chua (2000) noted the government plan to boost the number of research scientists from 7900 in 1986 to 13000 in 2000 . However, it is also clear that much of this demand can only be met through immigration rather than self-generation. Secondly, Singapore does not have much of a class of venture capitalists.

(ii) Supportive environment: These include basic infrastructure: transport and communications, science and technology parks, a climate that is attractive to knowledge workers (climate, cultural and leisure activities, schools, and being close to others like themselves), and a regulatory regime that supports innovation and risk-taking (low levels of regulations regarding working hours, relative ease in starting business, or taking 
business public, and bankruptcy laws that do not penalize to a high degree). Singapore's record is mixed on this dimension. The basic infrastructure is very good, but it is not clear that Singapore does very well in terms of creating a climate that is attractive to knowledge workers, and it is not clear whether either regulations or social norms encourage risk-taking. One aspect that is often thought to be crucial to the attraction of knowledge workers is an extremely free society with a free press. Singapore has been known to be rather heavyhanded with those who criticize the government. Further, the encouragement of entrepreneurial abilities requires both supportive legislation (bankruptcy laws) and a society in which failure is tolerated. Again, the extent to which this is true of Singapore is debatable.

Thus, despite its current successes, Singapore's government needs to contend with several fundamental issues about the nature of its society and democracy to facilitate this process. It is unclear as to whether Singapore's government-owned educational institutions can become like Stanford or the University of California, since it would require major changes in the universities, including autonomy, faculty management, teaching and research loads. It is not clear whether the innovative environment exists,

and although the government is mandating creativity in schools and college curriculums, creativity and innovation in business are a function of long term forces, including absolute democracy and freedom of expression and non controlled electoral systems. Further, innovation is also a function of the ability to fail, and it is not clear that society tolerates failure well in Singapore. It is also not clear that a climate of free expression valued by knowledge workers currently exists. There is a clear danger that the reasons for the success of the Singapore system in the short term, particularly government orchestration, may not serve it so well in the long term.

\section{TRANSFERABILITY OF THE SKILLS DEVELOPMENT MODEL}

Since rapid acceleration of skills development is a crucial imperative for many developing nations, successful systems like that of Singapore tend to b copied/adapted by other developing nations. Key aspects of Singapore's context ( small size, tight labor markets, export orientation, the need to attract foreign investment) are also present in other developing nations. Other developing nations may not have all the institutional 
preconditions noted in Singapore. Further, the processes that Singapore has been able to put in place may not be easily replicated by other nations. ${ }^{7}$.

What, then, are the lessons for other developing nations? It is an increasingly accepted axiom in industrial relations that attempts at transplanting successful systems from one country to another is bound to result in failure (Katz, Kuruvilla and Turner, 1993). Yet, several countries have shown interest in introducing the skills development system given its apparent success in Singapore. We would argue against transplantation, given that the national integrated skills development system in Singapore is successful because it is part of a unique institutional context where different institutions work together in a coordinated way, with a commonality of purpose, and with linkages to a host of other policies to deliver skills improvement. And, the factors that have caused success here may not quite cause the same success elsewhere.

However, there is much that might be of use to other developing nations. In particular we want to stress three major principles that might be applicable beyond Singapore's borders. First, the linkage (administratively and conceptually) between economic development and skills development. Second, the EDB's model of technology transfer, that takes advantage of the expertise of foreign investors to train local workers. Third, the fact that the private sector is induced to play a key role (in partnership with the government) both in terms of being part of the skills training process, but also in terms of training their own workforces. These three principles are important, and possibly transferable, although the specific institutions that other developing countries design to act on these principles may be very different.

\section{CONCLUSION}

Using a new framework we attempted to evaluate Singapore's acclaimed skills development system. We argued that the system is a good example of a concerted national integrated effort, since it involves private and public sectors, it occurs at multiple levels (educational institutions, vocational institutions, and within firms), it is linked to other national policies (e.g., economic development, technology transfer), and the various institutions appear to work together. We concluded that the Singapore system works well for its current needs and exhibits the needed pre-requisites to transform into higher skills equilibria. We have raised some issues about the long term sustainability of the system in 
the light of Singapore's own national plans for its future, noting in particular the fundamental changes that may be required if Singapore is to become another "Silicon Valley." Finally, we argue that the Singapore system is not easily replicable in other nations for a variety of contextual and institutional reasons, but that there are important principles that may be transferable. And although more research is necessary, we have also attempted to contribute to the development of a more general framework that can be used to evaluate national skills development efforts, since improving skills are so critical for developing nations. 


\section{REFERENCES}

Amsden, Alice H. 1989. Asia’s Next Giant. New York: Oxford University Press.

Ashton, D, Green, F., James, D., and Sung, J. 1999. Education and Training for Development in East Asia. The Political Economy of Skill Formation in Newly Industrializing East Asian Economies. Routledge: London and New York.

Azariadis, C and Drazen, A. 1991. "Threshold Externalities in Economic Development.” Quarterly Journal of Economics, 105, 501-26.

Barro, R.J.. 1997. Determinants of Economic Growth: A Cross-country Empirical Study. Cambridge, MA : MIT Press

Beaton, Albert 1996. Mathematics Achievement in the Middle School Years:

IEA's Third International Mathematics and Science Study. Boston, MA CSTEEP.

Behrman, J. 1997. "Simple Analytical Considerations for Skill Development for International Competitiveness.” In Godfrey, M (ed). Skills Development for International Competitiveness. Cheltenham, UK: Edward Elgar

BERI. 1999. Business Environment Risk Intelligence Report, BERI S.A., Switzerland.

Bishop. John. 1997. "What we Know about Employer Funded Training. A Review of the Literature.” Research in Labor Economics., Vol 16, pp. 19-87.

Castells, Manuel. 1992. "Four Tigers with a Dragon Head: A Comparative Analysis of the State, Economy and Society in the Asian Pacific Rim,” in Richard P. Appelbaum and Jeffrey Henderson (eds) States and Development in the Asian Pacific Rim. Newbury Park, California: Sage.

Culpepper, P.D., 1999. “The Future of the High-Skill Equilibrium in Germany.” Oxford Review of Economic Policy, Vol 15, no. 1, pp. 43-59.

Edwards. C. 1997. "State Failure or Market Failure? The Ten Steps to a Levy/Grant System.” In Godfrey, M (ed). Skills Development for International Competitiveness. Cheltenham, UK: Edward Elgar

Erickson, Christopher and Jacoby, Sanford. 2000. "Management Matters: Employer Networks and the Adoption of Human Resource Innovations.” Working Paper.

Erickson, Christopher and Kuruvilla, Sarosh. 2000. "Industrial Relations and the Asian Economic Crisis: An Analysis of the Short Term Impacts and Long Term Implications for Industrial Relations Systems.” In Global Integration and Challenges for Industrial 
Relations and Human Resource Management in the Twenty-First Century, International Industrial Relations Association Twelfth World Congress.

Finegold, David. 1999. “Creating Self Sustaining High Skill Ecosystems.” Oxford Review of Economic Policy, vol.15, no. 1, pp. 60-90.

Finegold, D. and Soskice, D. 1988. "The Failure of British Training: Analysis and Prescription,” Oxford Review of Economic Policy, vol. 4, no. 3, pp. 21-53.

Godfrey, M. 1997. “Introduction.” In Godfrey, M (ed). Skills Development for International Competitiveness. Cheltenham, UK: Edward Elgar

Hiers, W. and Arudsothy, P. 1999. "From Ostensible Voluntarism to Interventionism in Malaysian Industrial Relations: The Colonial experience as an Important Variable.” In S. Kuruvilla and B. Mundell (Eds.), The Institutionalization of Industrial Relations in Developing Economies. Stamford, CT: Jai Press.

International Institute for Management Development (IMD). 2000. World Competitiveness Yearbook. Lausanne: IMD.

James, D. , Sung, J., Green, F. and Ashton, D. 1999. "The Role of the State in Skill Formation: Evidence from the Republic of Korea, Singapore, and Taiwan.” Oxford Review of Economic Policy, Volume 15. No 1., pp 82-96.

Katz, Harry, Kuruvilla, Sarosh, and Turner, Lowell. 1993. "Trade Unions and Collective Bargaining.” In Arvil Van Adams, ed., Impediments to Competitive Labor Markets: An Overview of Policy and Research Issues. Washington, D.C.: The World Bank.

Katzenstein, Peter. 1985. Small States in World Markets: Industrial Policy in Europe. Ithaca: Cornell University Press.

Keep, E., and Mayhew, K. 1999. “The Assessment: Knowledge, Skills, and Competitiveness.” Oxford Review of Economic Policy, vol 15, no 1, pp 1-15

Kenney, Martin. 2000. Understanding Silicon Valley: The Anatomy of an Innovative Region. Palo Alto: Stanford University Press.

Koike, K. 1996. “Globalization, Competitiveness and Workers’ Skills.” Proceedings of the regional Meeting of the Asian Industrial Relations Association, Taipei, Taiwan, September 1996

Krugman, Paul. 1994. “The Myth of Asia's Miracle.” Foreign Affairs.

Kuruvilla, S. 1996 "Linkages Between Industrialization Strategies and Industrial Relations / Human Resource Policies: Singapore, Malaysia, the Philippines, and India.” Industrial and Labor Relations Review, vol. 49, no. 4, pp. 635-657. 
Kuruvilla, S. 1997. Globalization and Employment Relations: A Framework for Research. Bangkok. ILO EASTMAT.

Kuruvilla, S. and Rodney Chua. 2000. "How do Nations Increase Workforce Skills? Factors Influencing the Success of the Singapore Skills Development System.” Global Business Review, Volume 1, no. 1, pp. 11-49.

Lucas. R. E. 1988. “On the Mechanics of Economic Development.” Journal of Monetary Economics, vol. 21, pp. 3-42.

Romer, P. 1986. “Increasing Returns and Long Run Growth.” Journal of Political Economy, vol. 94, pp. 1002-36.

Schein, Edgar. 1996. Strategic Pragmatism: The Culture of Singapore's Economic Development Board. Cambridge: MIT Press.

Singh, A. 1990. "The Lost Decade: The Economic Crisis of the Third World in the 1980s. How the North Caused the South's Crisis.” Contention: Debates in Society, Culture, and Science, vol. 103, pp.136-168.

Solow, R. 1956. “A Contribution to the Theory of Economic Growth.” Quarterly Journal of Economics, vol. 70, pp. 65-94.

Streeck, W and Schmitter, Philippe C. 1985. Private Interest Governments: Beyond Market and State. Beverly Hills and London : Sage.

Vente, R.E. \& Chow, K.B. 1984. Education and Training for Industrial Development in Singapore and other ASEAN Countries: The Role of Private Corporations, Foreign Aid, and Regional Cooperation. Baden-Baden: Nomos Verlagsgesellschaft and Singapore: Maruzen Asia

Wood, A. 1994. "Skill, Land, and Trade: A Simple Analytic Framework.” Working Paper No. 1. Brighton, Sussex: Institute for Development Studies.

World Economic Forum. 2000. Global Competitiveness Report. Geneva: World Economic Forum.

Young, A. 1995. "The Tyranny of Numbers: Confronting the Statistical Realities of the East Asian Growth Experience.” Quarterly Journal of Economics, vol. 110, no. 3, pp. 641-680. 
Table 1: General Macro Indicators: Singapore, Selected Years.

\begin{tabular}{|c|c|c|c|c|c|}
\hline Year & $\begin{array}{c}\text { GDP } \\
\text { Growth Rate }\end{array}$ & $\begin{array}{l}\text { Per Capita GDP } \\
\text { at Current } \\
\text { Market Prices in } \\
\text { Singapore \$ }\end{array}$ & $\begin{array}{c}\text { Growth } \\
\text { Rates of } \\
\text { Foreign } \\
\text { Direct } \\
\text { Investment }\end{array}$ & $\begin{array}{c}\text { Change in } \\
\text { Labor } \\
\text { Productivity }\end{array}$ & $\begin{array}{c}\text { Literacy } \\
\text { Rate }\end{array}$ \\
\hline 1965 & 6.6 & 1,567 & & & 60.2 \\
\hline 1970 & 13.4 & 2,798 & & & 68.9 \\
\hline 1975 & 4.0 & 5,941 & & & 76.2 \\
\hline 1980 & 9.7 & 10,394 & & & 82.3 \\
\hline 1985 & -1.6 & 14,226 & & & \\
\hline 1986 & 2.3 & 14,225 & 10.5 & & \\
\hline 1987 & 9.7 & 15,487 & 21.2 & & \\
\hline 1988 & 11.6 & 17,819 & 19.5 & 5.0 & 87.7 \\
\hline 1989 & 9.6 & 19,854 & 14.7 & & 88.4 \\
\hline 1990 & 9.0 & 21,812 & 21.3 & & 89.1 \\
\hline 1991 & 7.1 & 23,604 & 9.4 & & 90.3 \\
\hline 1992 & 6.5 & 24,730 & 3.84 & & 90.3 \\
\hline 1993 & 12.7 & 28,105 & 10.77 & 9.1 & 90.8 \\
\hline 1994 & 11.4 & 31,175 & 18.86 & 6.4 & 91.3 \\
\hline 1995 & 8.0 & 33,404 & 12.9 & 3.3 & 91.8 \\
\hline 1996 & 7.6 & 34,928 & 11.5 & 1.2 & 92.2 \\
\hline 1997 & 8.5 & 36,963 & 19.2 & 2.2 & 92.8 \\
\hline 1998 & 0.1 & 35,040 & & -2.3 & 93.1 \\
\hline 1999 & 5.9 & 35,958 & & 5.8 & \\
\hline 2000 & 9.9 & 39,585 & & & \\
\hline
\end{tabular}

Table 2: Unemployment and Job Vacancies, 1996-2000

\begin{tabular}{|l|l|l|l|l|}
\hline Year & $\begin{array}{l}\text { Unemployment } \\
\text { Rate }\end{array}$ & $\begin{array}{l}\text { Unemployment } \\
\text { Numbers (000s) }\end{array}$ & $\begin{array}{l}\text { Job Vacancy } \\
\text { Rate }\end{array}$ & $\begin{array}{l}\text { Job Vacancies } \\
\text { (000s). }\end{array}$ \\
\hline 1996 & 2.0 & 37.3 & 4.8 & 44.2 \\
\hline 1997 & 1.8 & 34.8 & 4.4 & 42.0 \\
\hline 1998 & 3.2 & 62.7 & 1.9 & 18.3 \\
\hline 1999 & 3.5 & 69.5 & 2.2 & 20.0 \\
\hline 2000 & 3.1 & 65.4 & 2.8 & 27.6 \\
\hline
\end{tabular}


Table 3. Educational Distribution of Singapore Workforce

\begin{tabular}{|l|c|c|c|c|c|c|}
\hline \multirow{2}{*}{$\begin{array}{l}\text { Highest } \\
\text { Qualification } \\
\text { Attained }\end{array}$} & \multicolumn{2}{|c|}{$25-34$} & \multicolumn{2}{c|}{$35-44$} & \multicolumn{2}{c|}{$45-54$} \\
\cline { 2 - 7 } & 1990 & 2000 & 1990 & 2000 & 1990 & 2000 \\
\hline Total (\%) & 100.0 & 100.0 & 100.0 & 100.0 & 100.0 & 100.0 \\
\hline No Qualification & 12.2 & 4.3 & 23.9 & 9.7 & 49.7 & 19.8 \\
\hline Primary & 31.2 & 14.1 & 35.2 & 27.1 & 27.4 & 32.7 \\
\hline Secondary & 36.9 & 25.7 & 26.3 & 30.9 & 13.6 & 26.1 \\
\hline Upper Secondary & 7.6 & 20.6 & 7.0 & 15.1 & 4.6 & 12.5 \\
\hline Polytechnic & 4.9 & 10.9 & 2.4 & 4.7 & 1.2 & 2.1 \\
\hline University & 7.2 & 24.4 & 5.2 & 12.4 & 3.5 & 6.7 \\
\hline
\end{tabular}

Table 4. Average Annual Growth Rate of Graduates from Different Institutions, 19881998.

\begin{tabular}{|l|l|}
\hline Institutions & $\begin{array}{l}\text { Average Annual Growth } \\
\text { Rates, 1988-1998 }\end{array}$ \\
\hline Universities & $7.6 \%$ \\
\hline NIE & $12.4 \%$ \\
\hline Polytechnics & $6.5 \%$ \\
\hline ITE & $-2.3 \%$ \\
\hline PSB & $4.7 \%$ \\
\hline SDF training Places & $5.6 \%$ \\
\hline
\end{tabular}

Note: ITE enrolment decreased from 14995 graduates in 1993 to a low of

8233 graduates in 1996, but has increased thereafter to 13337 graduates in 1998. 
Table 5. Rankings on HR dimensions in the Competitiveness Reports.

\begin{tabular}{|l|l|l|l|l|}
\hline Competitiveness Report & HR Dimensions & $\begin{array}{l}1998 \\
\text { Rank }\end{array}$ & $\begin{array}{l}1999 \\
\text { Rank }\end{array}$ & $\begin{array}{l}2000 \\
\text { Rank }\end{array}$ \\
\hline $\begin{array}{l}\text { Global Competitiveness } \\
\text { Report (World Economic } \\
\text { Forum) }\end{array}$ & $\begin{array}{l}\text { Efficiency and } \\
\text { flexibility of labor } \\
\text { markets }\end{array}$ & 1 & 1 & 1 \\
\hline $\begin{array}{l}\text { World Competitiveness } \\
\text { Yearbook (International } \\
\text { Institute for Management } \\
\text { Development) }\end{array}$ & $\begin{array}{l}\text { Availability and } \\
\text { qualifications of human } \\
\text { resources (population } \\
\text { and labor force } \\
\text { characteristics, } \\
\text { unemployment, } \\
\text { education, quality of } \\
\text { life, attitudes and } \\
\text { values) }\end{array}$ & 1 & 4 & 5 \\
\hline
\end{tabular}

http://www.psb.gov.sg/statistics_faq/statistics/competitiveness.html

Table 6. Firm Level Training through SDF in Singapore

\begin{tabular}{|l|l|l|l|l|}
\hline & 1995 & 1996 & 1997 & 1998 \\
\hline $\begin{array}{l}\text { Training } \\
\text { Investment as } \\
\text { Percentage of } \\
\text { Payroll }\end{array}$ & 3.6 & 3.6 & 3.6 & 3.6 \\
\hline $\begin{array}{l}\text { Number of } \\
\text { hours of } \\
\text { training per } \\
\text { employee }\end{array}$ & 34 & 40 & 32 & 40 \\
\hline $\begin{array}{l}\text { Training Places } \\
\text { per Employee }\end{array}$ & 0.3 & 0.3 & 0.3 & 0.3 \\
\hline
\end{tabular}

Table 7. Turnover Rates in Singapore, 1988-1999

\begin{tabular}{|l|l|l|}
\hline $1988=3.9$ & $1993=3.2$ & $1994=3.1$ \\
\hline $1995=3$ & $1996=2.8$ & $1997=2.7$ \\
\hline $1998=2.1$ & $1999=2.2$ & $2000=2.5$ \\
\hline
\end{tabular}

Source: YearBook of Labor Statistics, pp 51. 
${ }^{1}$ In fact, it appears established as a model in Southeast Asia, as Malaysia has already adopted parts of the Singapore system.

${ }^{2}$ The Global Competitiveness Report (The World Economic Forum, 2000) ranking of countries found Singapore to be first in international competitiveness from 1997 to 1999 and second (to the U.S.) in 2000. Another competitiveness ranking by The International Institute for Management (IMD, 2000) placed Singapore second in World Competitiveness, just behind the U.S. over the same three-year period. In the latest Business Environment Risk report (BERI, 1999) Singapore's workforce scored highest out of 49 countries in terms of the relative productivity ratio. Recent comparative research on education through the third international math and science study (Beaton, 1996) placed Singaporean 13 year olds at the top of all nations in terms of both science and math scores.

${ }^{3}$ Yet, as we noted, the mid 1990s witnessed complaints from employers that the education system produced competent engineers and technicians, but not creative entrepreneurs and risk takers. Although no systematic and reliable measure of creativity of high school graduates exists, the government has prioritized education reform to increase creativity, through a number of different interventions, such as changing the examination structure, training teachers, integrating project work with classroom learning, and encouraging continuous learning, as we discussed earlier.

${ }^{4}$ Note, however, that the regional economic crisis might have contributed to the low turnover rates post-1997.

${ }^{5}$ Behind these basic goals are more detailed action plans that can be found in the following sources: Productivity 2000 Campaign, The Committee on Singapore's Competitiveness, the CSC Subcomittee on Manpower and Productivity, The Singapore Economic Development Board's Industry 21 Initiative, the Ministry of Trade and Industry's Economic Vision for the Future, and the PSB's action program to sustain long term productivity growth, coupled with the National Trade Union Congress's productivity push program.

${ }^{6}$ The "interdependence" factor clearly seems to be present in Singapore.

${ }^{7}$ Though, on the other hand, we also note that Singapore's population is not much smaller than Scandinavian countries with well recognized "national” models. 